\title{
VOC emissions from the combustion of low-grade lignocellulosic waste
}

Dimitriou, Athanasios; Roberts, Paula; Ormondroyd, Graham

\section{International Wood Products Journal}

Published: 01/10/2018

Peer reviewed version

Cyswllt i'r cyhoeddiad / Link to publication

Dyfyniad o'r fersiwn a gyhoeddwyd / Citation for published version (APA):

Dimitriou, A., Roberts, P., \& Ormondroyd, G. (2018). VOC emissions from the combustion of low-grade lignocellulosic waste. International Wood Products Journal.

\footnotetext{
Hawliau Cyffredinol / General rights

Copyright and moral rights for the publications made accessible in the public portal are retained by the authors and/or other copyright owners and it is a condition of accessing publications that users recognise and abide by the legal requirements associated with these rights.

- Users may download and print one copy of any publication from the public portal for the purpose of private study or research.

- You may not further distribute the material or use it for any profit-making activity or commercial gain

- You may freely distribute the URL identifying the publication in the public portal ?
}

Take down policy

If you believe that this document breaches copyright please contact us providing details, and we will remove access to the work immediately and investigate your claim. 


\title{
VOC emissions from the combustion of low grade lignocellulosic waste
}

\author{
A. Dimitriou*1, P. Roberts ${ }^{2}$, G.A. Ormondroyd ${ }^{1}$ \\ ${ }^{1}$ BioComposites Centre, Bangor University, Bangor, UK \\ ${ }^{2}$ School of the Environment, Natural Resources and Geography, Bangor University, \\ Bangor, $U K$ \\ *Corresponding author, email a.dimitriou@bangor.ac.uk
}




\section{VOC emissions from the combustion of low grade lignocellulosic waste}

The European Commission in order to reduce the greenhouse gas emissions is promoting the usage of renewable energy techniques and the replacement of fossil fuels with biomass. It is estimated that two thirds of the renewable energy production will be derived by biomass by 2020 (European Commission, 2012). However, the increasing need for biomass fuels generates the debate of sustainability of biofuels like corn-based ethanol as the impact of the potential land use change generates more greenhouse emissions than the emissions which can be reduced by its usage. In response to the this concern, the usage of biomass wastes for biofuels does not affect the land use changes and therefore improves the sustainability potential of biomass fuels (Searchinger et al, 2008).

Energy recovery by wood waste is considered a non-contributor method to greenhouse gas emissions. However, wood waste might contain contaminates which could release toxic volatile compounds. Also the produced particulates and ash, during combustion, may contain non-volatile compounds such as heavy metals (Pitman 2006). This study investigates the gaseous VOC emissions during combustion of low grade lignocellulosic waste in order to determine the wood wastes suitability as a bio-fuel source.

Keywords: Wood waste; wood combustion; VOCs; biomass fuel; energy recovery; GC-MS; GC-FID

\section{Introduction}

The United Nations Framework Convention on Climate Change met in 1992 to discuss the various methods to stabilize the greenhouse gas concentrations in the atmosphere at a level of anthropogenic emissions that would not affect the climate system. The convention discussed many methods of stabilization of greenhouse gas emissions, including the use of green technologies for the generation of energy (wind, solar and wave power) and the use of carbon capture and storage (CCS) and the reduction of our reliance on fossil fuels. 
Paragraph: use this for the first paragraph in a section, or to continue after an extract.

In response to the growing concerns around climate change the European Union has set a target of reducing the emissions by $80 \%$ to $95 \%$ from the values of 1990 by 2050 with an intermediate target of $20 \%$ reduction by 2020 (European Commission, 2012). The European Commission estimates that two thirds of the renewable energy production will be derived by biomass by 2020. In a separate attempt to reduce green gas emissions and pollution, the EU Landfill directive (1999/31/EC) has resulted in increased pressures on National and Regional Governments to divert most wastes from landfill.

Parikka (2004) estimated that the world's total above ground timber biomass reserve to be $420\left(10^{9}\right)$ tonnes and the estimated the global production of wood fuel to be approximately $1,634\left(10^{6}\right)$ tonnes with $90 \%$ of this was produced in developing countries. In contrast, the world production of round wood $\left(1,515\left(10^{6}\right) \mathrm{m}^{3}\right)$ was dominated by developed countries. However, of the $1,515\left(10^{6}\right) \mathrm{m}^{3}$ about $40 \%$ is classed as primary or secondary processing residues and suitable for composites or energy production.

The wood usage in its various applications results in a significant amounts of wood waste. The wood waste is produced during multiple stage of its processing product cycle; harvesting, processing, manufacture and disposal of final product. The wood waste is either recycled or used for energy production. It is estimated that UK produces 4.6 million tonnes of wood waste annually (Greenhalf M. and Brown M., 2012). Wood wastes according to PAS 111:2012 standards are categorised in four different grades. Category A is referred to clean without or minimal amounts of coatings and fixing which is mainly recyclable. Category B is a mixture of category A wood waste and wood derived for construction and demolition activities and solid wood 
furniture waste. Category B is used for recycling and fuel source. Category C wood waste contain municipal wood waste, furniture, fencing and wood based panels. Because the high content of contaminates including metal, paints, coatings, preservatives, glass, glues and rubber which makes the category $\mathrm{C}$ wood waste suitable only for combustion. The last category D wood waste includes CCA and creosote treated wood which is not possible to be reused in any manner.

The debate around sustainability and the expansion of biomass utilisation (as a replacement for fossil-based resources) has tended to focus more on biofuels development than biomaterials exploitation to date. Searchinger et al (2008) famously highlighted the potential land use change impacts associated with first generation (i.e. food crop-based) bio-ethanol development, and since then a wide range of secondary or advanced biofuels have been investigated using non-food biomass as a feedstock. Much of this research has focused on the exploitation of lignocellulosic material in woody and herbaceous biomass (e.g. Kim et al, 2016; Park et al, 2016, Jones et al, 2014; Zhu and Pan, 2010) as well as from agricultural residues such as corn stover (e.g. Chen et al, 2015) and wheat and rice straws (Gonzalez et al, 2011; Han et al, 2015).

In terms of forestry wood waste, there has been much focus on bio-energy development, and on wood pellet markets in particular. Sjølie and Solberg (2011) assessed GHG emissions associated with European wood pellet production, and McKechnie et al (2011) have considered forest bio-energy in relation to forest carbon stores. Their study considered both wood fuel pellets and bio-ethanol production from woody biomass, and highlighted the significance of stored carbon in the overall carbon balance of the forest bio-energy lifecycles.

Given the competing pulls on wood waste biomass, Bringezu et al (2012) have proposed an approach to account for international timber flows, based on the concept of 
safe operating space. In doing so, they highlighted the need for joined-up biofuels and bio-materials policies, calling for the development of sustainable biomass action plans, as part of the broader economy-wide sustainability planning process.

Even though energy recovery from wood waste does not contribute to greenhouse gas emissions, it might have other environmental impacts because of the contained contaminants which could be released as toxic volatile compounds during combustion. The produced particulates and the ash may also contain non-volatile compounds such as heavy metals (Pitman 2006). In order to determine the appropriateness of wood wastes as a bio-fuel source, this study examines the gaseous VOC emissions during combustion.

\section{Materials and methods}

\section{Materials}

Samples

The sample wastes which were used in this study were obtained from a waste recycling and reprocessing company Greenworld Ltd, Kings Lynn, Norfolk, UK. Four different waste materials were subjected to determination of VOC emission compounds during combustion. The selected sample wastes were fine flour category $\mathrm{C}$ wood waste, shredded category $\mathrm{C}$ wood waste, paper mill waste and semi-composted wood particles from garden waste. The sourced materials were stored as different piles in an open space at the wood waste processing facility of Greenworld.

The category $\mathrm{C}$ wood waste, contained coated and treated timber, nails and metal fixings, coatings and glues, glass, grit, plastics and rubber. The wood waste was shredded on site into particles of $30 \mathrm{~cm}$ size. By further processing of the shredded category $\mathrm{C}$ wood waste, a fine dust which was piled separately was also produced. 
Shredded category $\mathrm{C}$ wood waste was collected from the bottom, middle and top of the pile and mixed together to best represent any variability within the pile. In order to avoid the collection of material containing external contamination, the samples were collected from a depth of $50 \mathrm{~cm}$ into pile. The same sampling procedure was used to collect fine flour category $\mathrm{C}$ waste wood and paper mill waste.

Garden waste derives from civic amenity site or collected from households and contains grass cuttings, leaves and woody material. The garden waste is used for soil conditioners, mulch, top soil constituent and turf dressing by composting method. The larger wood particles which are usually contained in this type of waste, are not easily compostable and therefore after the final screening stage of the composting process the large un-composted wood particles are collected and piled separately. Those semicomposted wood particles were also collected from a separate stored pile in the same manner as mentioned before.

The final product of Greenworld is a fine flour free from contaminates. Therefore all samples had to be a fine flour before testing. The shredded category $\mathrm{C}$ wood waste and the semi-composted wood waste were cut into small pieces and any possible contaminates (glass and metal) were removed by hand. The small clean sample particles were then milled into a fine flour. The paper waste was difficult to be milled and therefore was grounded by pestle and mortar.

\section{Combustion apparatus}

The sample combustion was done with the apparatus presented in Figure 1. The samples were placed in ceramic crucibles and combusted in a Carbolite 12/13 oven. The smoke was drawn upwards by a venturi vacuum pump with an 80-100 psi of air supply. The smoke was forced by the vacuum through a $47 \mathrm{~mm}$ Millipore glass fibre filter with $0.7 \mu \mathrm{m}$ pore size in order to collect any particulates contained into the smoke. The 
filtered smoke was then driven into a desorption tube containing Tenax TA and carboxen 1018 absorbent trap which was collecting the VOCs.

Tenax TA is a porous material based on 2,6-diphenylene oxide polymer which absorbs VOC molecules with a size range of 5 to 20 carbon and carboxen 1018 a high purity porous carbon polymer which absorbs VOCs with size rage of 2 to 5 carbons.

\section{VOC analysis equipment}

In order to identify the chemical composition of the VOCs which were collected by the absorbent trap a Clarus 480 Gas Chromatography with Flame Ionization Detector (GC-FID) and a Clarus 680 PerkinElmer Gas Chromatography with Mass Spectroscopy (GC-MS) were used.

\section{Methods}

\section{Combustion procedure}

The samples were dried in an oven at $80{ }^{\circ} \mathrm{C}$ until constant mass (around $16 \mathrm{hrs)}$ to remove the contained moisture which could affect the materials combustion properties. The reason of using $80^{\circ} \mathrm{C}$ instead of $105^{\circ} \mathrm{C}$ was to ensure that no chemical changes will occur during the drying phase. Ceramic crucibles filled with dry samples were placed into the furnace and the heat was switched on. When the furnace had reached the set temperature it was left running for 5 min before sampling the emissions in order to produce sufficient amount of smoke to be collected. The vacuum pump and the sorbent trap were assembled separately from the glass filter with the exhaust hood and the furnace in order to control the moment of the sampling. The compressor was switched on prior sampling to reach full pressure and then placed on the filter for sampling. The sampling duration was $1 \mathrm{~min}$. After the first sampling the absorbent trap 
was removed and replaced with a new one and the sampling procedure was repeated for another two times in order to produce three replicates for every run.

The weighed ceramic crucibles were filled with the dry samples and weighed again before and after the combustion for the determination of the remained ash. The glass filter was also weighed before and after testing in order to determine any possible particulate deposition on the filter.

The combustion temperatures were chosen after a short test in which the samples were ignited with firelighters and the temperature was measured by thermal couples. The highest temperature $\left(850^{\circ} \mathrm{C}\right)$ was observed at the semi-composted wood; the second highest temperature was observed during the combustion of category $\mathrm{C}$ wood waste while paper had the lowest temperature of $700{ }^{\circ} \mathrm{C}$. Despite the highest achieved temperature of each type of waste a few intermediate temperatures were also chosen because during the combustion, each waste spent a significant time at these temperatures before and after the highest temperature was achieved. In case of paper the combustion was fast and therefore only the highest temperature was selected for this study. In particular for the category $\mathrm{C}$ wood waste the combustion temperatures were $400{ }^{\circ} \mathrm{C}, 600{ }^{\circ} \mathrm{C}$ and $800{ }^{\circ} \mathrm{C}$. The semi-composted wood was combusted at $500{ }^{\circ} \mathrm{C}$ and $850{ }^{\circ} \mathrm{C}$ and the paper waste at $700{ }^{\circ} \mathrm{C}$

\section{GC-MS analysis method}

The GC-MS analysis was based on solvent desorption of the VOCs which were contained in the sorption tubes. Each tube was washed several times with methanol in order to ensure that all the trapped VOCs were dissolved. The VOC containing methanol solution was then analysed by GC-MS with a DB5 column. The separated compounds, where transferred with nitrogen carrier gas, to the GC and MS which were further analysed. The compounds were identified by characteristic fragmentation 
patterns and matched against the National Institute of Standards and Technology (NIST) mass spectral library.

\section{GC-FID analysis method}

The VOCs which were trapped in the tenax and the carboxen tubes were thermally desorbed into the GC-FID by quickly heating to $200{ }^{\circ} \mathrm{C}$ in a stream of nitrogen gas. The column which was used was the same type with the GC-MS (DB5

column). The volatile compounds were released gradually from the sorption tube and collected in an internal cold trap at $-30{ }^{\circ} \mathrm{C}$. The collected volatile compounds were subsequently heated and released onto the GC where they were separated according their vapour pressure. The FID further characterised the VOC compounds by the ion production during oxygen flame combustion.

\section{Results and discussion}

\section{GC-MS analysis}

Table 1 presents the GC-MS results of each waste type despite the combustion temperature. The reason for this analysis is the qualification of the VOCs according to their retention time. The obtained data will be used in combination with the GS-FID for the quantification of the combustion products. The values are the matching probability percentage with the NIST database. The compounds which are presented in Table 1 were selected as the highest probability percentage. The less complex emissions were observed at both fine and shredded category $\mathrm{C}$ wood waste. However, despite the fact that both fine and shredded category $\mathrm{C}$ wood waste were supposedly derived from the same source material there were only two compounds matching in their emissions. Those compounds were the pyridine and benzaldehyde which are known to be released by plants decomposition and combustion. Therefore, as was expected, those two 
compounds were also observed in the case of semi-composted wood. Both compounds are used as industrial solvents. Pyridine which was present in all samples, including paper waste, is a hazardous and carcinogenic volatile compound. Benzaldehyde as phenol are aromatic compounds that could be derived from contaminants but also from lignin. In the fine flour category $\mathrm{C}$ wood waste and the paper waste there were phenol compounds observed which were absent in the shredded and composted wood waste.

3,5, dithiahexanol 5,5, dioxide and 6-phenyl tetrahydro 1,3, oxazine-2-thione 4methyl were only observed in the case of the fine flour category $\mathrm{C}$ wood waste. Those compounds might be derived from contaminants and could be more concentrated in the case of fine flour in contrast to the other samples. This could be explained by the fact that fine flour category $\mathrm{C}$ wood waste was industrially produced and therefore, contaminates removal could not be achieved at the same efficiency as was done in the laboratory with the shredded category $\mathrm{C}$ wood waste.

Naphtho (2, 1-b) furan was only observed in the case of the shredded category C wood waste. Another compound which is common in all samples except of the fine flour category $\mathrm{C}$ wood waste was the Heptane which could be derived from the cellulose decomposition. The presence of heptane was expected to be found during wood combustion (Mcdonald et al, 2000). Heptane is also used in adhesives, sealants, paints and coatings, and is a hazardous toxic substance. Also 2-methyl phenol which is also known as o-cresol was present in shredded category $\mathrm{C}$ wood waste and paper waste. O-cresol is a possible carcinogen and hazardous VOC and is used in adhesives, sealants, paints and coatings. 1-methylene-1H-indene was observed in shredded category $\mathrm{C}$ wood waste and into the semi-composted wood.

Acetophenone, 2-ethyl-1-hexanol, 3-methyl phenol and 1, 2, 6, 6, 9, 9, heptamethyl-10-methyloene-spiro $(2,7)$ dec-4-ene were only observed in the case of the 
semi-composted wood. Bi-phenyl, which occurs naturally in certain plants and is used as plant disease control, was also observed in the semi-composted wood and into the paper waste emissions.

The combustion of paper waste produces several different VOC compounds. The large variety of compounds that emitted during the waste paper combustion could be explained by the several treatments which occur during paper production, printing recycling and deinking.

\section{GC-FID analysis}

GC-FID analysis revealed that some VOCs elute in shorter time than could be identified by GC-MS. The first peak on the GC-MS was appeared after 3.7 min while the GC-FID showed peaks from $1.82 \mathrm{~min}$ and therefore those peaks could not be identified. It is possible that those early eluted compounds which were observed during the GC-FID analysis to have been vaporised during the solvent desorption procedure which took place at the GC-MS analysis. The individual amounts of the emitted VOCs are presented in Table 2, 3 and 4.

From the GC-FID results it is obvious that the identified VOCs were differ from the VOCs observed by GC-MS analysis. This is because of the different temperatures used for this analysis. The GC-MS analysis showed the possible produced VOCs during combustion without taking into account the temperature that can be achieved by burning these waste samples. Therefore, the results of the GC-FID represent the actual VOCs which will be produced when using those samples as burning fuels.

According to Figure 2 it is obvious that the VOCs are reducing at higher combustion temperatures. As was expected the volatile compounds were decomposing in a pyrolysis procedure to smaller and simpler hydro carbon compounds resulting to smaller amount of non-flammable VOCs. Biomass pyrolysis is starting at around 160- 
$250{ }^{\circ} \mathrm{C}$ and as the temperature rises there is more gas production than VOCs and tar (Williams et al 2012). It is also interesting that the semi-composted wood showed higher amount of VOC between $500{ }^{\circ} \mathrm{C}$ and $850{ }^{\circ} \mathrm{C}$ than the category wood waste C. It was expected that the wood waste would resulted to higher VOCs because of the presence of contaminates. However lower temperatures might revealed a complete different trend. It is hypothesised that the contained contaminates were pyrolysed in a lower than the $600{ }^{\circ} \mathrm{C}$ temperature and the low line which appears in Figure 2 derives as a statistical error. However it is important to point out that the total amount of emitted VOCs by the combustion of category $\mathrm{C}$ wood waste was less than half of the amount emitted by semi-composted wood. The combusted paper waste at $700{ }^{\circ} \mathrm{C}$ seemed to produce the highest amount of VOCs in contrast to the other 2 samples.

\section{Conclusions}

The combustion emissions from category $\mathrm{C}$ wood waste appeared to have similar VOC compounds with the semi-composted wood. The paper waste showed extremely higher variety of VOC compounds in contrast to category $\mathrm{C}$ wood waste and semi-composted wood waste.

Some of the highest VOCs amounts were not identified as the compounds were only detected by GC-FID and were absent in the GC-MS analysis. It was observed that as the temperature increases the total amount of VOCs were reduced. Also compounds with lower vapour pressures which were absent in lower combustion temperatures were started to emit and the higher vapour pressure compounds slowly fade. It was hypothesised that as the combustion temperature increases the VOCs compounds were pyrolysed and transformed to higher vapour pressure compounds. 
Acknowledgments

We would like to thank R. Thomas and D. Till for their help to conduct the experimental work. This study was funded by Knowledge Economy Skills Scholarships (KESS). Knowledge Economy Skills Scholarships (KESS) is a pan-Wales higher level skills initiative led by Bangor University on behalf of the HE sector in Wales. It is part funded by the Welsh Government's European Social Fund (ESF) convergence programme for West Wales and the Valleys.

Financial support from the Knowledge Transfer Partnerships programme (KTP) (KTP010519) is currently funding the correspondence author. KTP aims to help businesses to improve their competitiveness and productivity through the better use of knowledge, technology and skills that reside within the UK Knowledge Base. The KTP was funded by the Technology Strategy Board and Welsh Government.

\section{References}

Bringezu S, O’Brien M, Schütz H (2012) Beyond biofuels: Assessing global land use for domestic consumption of biomass A conceptual and empirical contribution to sustainable management of global resources. Land Use Policy. 29:224- 232

Chen X, Shekiro J, Pschorn T, Sabourin M, Tucker MP, Tao L. (2015) Technoeconomic analysis of the deacetylation and disk refining process: characterizing the effect of refining energy and enzyme usage on minimum sugar selling price and minimum ethanol selling price. Biotechnol Biofuels. 8:173

European Commission. (2012). Roadmap 2050. DOI: 10.2833/10759

Gonzalez R, Jameel H, Chang H, Treasure T, Pirraglia A, Saloni D. (2011) Thermo-mechanical pulping as a pretreatment for agricultural biomass for biochemical conversion. BioResources. 6(2):1599-1614.

Greenhalf M. and Brown M. (2012). The Business Case for Wood Waste Collection Hubs: Final report. WRAP. http://www.wrap.org.uk/

Han Q, Jin Y, Jameel H, Chang H, Phillips R, Park S. (2015) Autohydrolysis pretreatment of waste wheat straw for cellulosic ethanol production in a co-located straw pulp mill. Applied Biochemistry and Biotechnology. 175:1193-1210. 
Jones BW, Venditti R, Park S, Jameel H. (2014) Comparison of lab, pilot, and industrial scale low consistency mechanical refining for improvements in enzymatic digestibility of pretreated hardwood. Bioresource Technology 167:514-520.

Kim SM, Dien BS, Singh V (2016) Promise of combined hydrothermal/chemical and mechanical refining for pretreatment of woody and herbaceous biomass. Biotechnol Biofuels 9:97

Mcdonald J. D., Zielinska B., Fujita E. M., Sagebiel J. C., Chow J. C. and Watson J. G. 2000. Fine particule and gaseous emission rates from residential wood combustion. Environmental Science \& Technology. 34:2080-2091

McKechnie J, Colombo S, Chen J, Mabee W, MacLean HL (2011) Forest Bioenergy or Forest Carbon? Assessing Trade-Offs in Greenhouse Gas Mitigation with Wood-Based Fuels. Environ. Sci. Technol. 45:789-795.

Parikka M. (2004). Global biomass fuel resources. Biomass and Bioenergy $27: 613-620$

Park J, Jones B, Koo B, Chen X, Tucker M, Yu J-H, Pschorn T, Venditti R, Park S. (2016) Use of mechanical refining to improve the production of low-cost sugars from lignocellulosic biomass. Bioresource Technology 199:59-67.

PAS 111:2012. Specification for the requirements and test methods for processing waste wood.

Pitman R. M. (2006). Wood ash use in forestry-a review of environmental impacts. Forestry. 79(5):563-588

Searchinger T, Heimlich R, Houghton RA, Dong F, Elobeid A, Fabiosa J, Tokgoz S, Hayes D, Yu T-H (2008) Use of U.S. croplands for biofuels increases greenhouse gases through emissions from land-use change. Science, 319:1238-1240 
Sjølie HK and Solberg B (2011) Greenhouse gas emission impacts of use of Norwegian wood pellets: a sensitivity analysis. Environmental Science and Policy, $14: 1028-1040$

United Nations (1992). United Nations Framework Convention on Climate Change, FCCC/INFORMAL/84, GE.05-62220 (E) 200705

William A., Jones J. M., Ma L. and Pourkashanian M. (2012). Pollutans from combustion of solid biomass fuels. Progress in Energy and Combustion Science. 38(2):113-137

Zhu JY and Pan XJ. (2010) Woody biomass pretreatment for cellulosic ethanol production: technology and energy consumption evaluation. Bioresource Technology. 101:4992-5002. 
Table 1: Emission compounds as detected by GC-MS. The values are the Probability $(\%)$

\begin{tabular}{|c|c|c|c|c|}
\hline Compound & 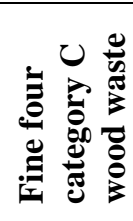 & 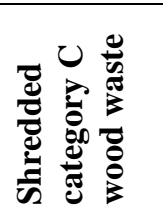 & 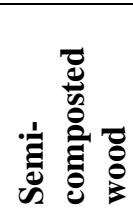 & 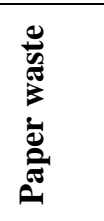 \\
\hline Heptane & & $74.4 \%$ & $48 \%$ & $71 \%$ \\
\hline 3,5, dithiahexanol 5,5, dioxide & $36.7 \%$ & & & \\
\hline$\alpha$-L-galactopyranoside, methyl 6-deoxy & & & & $33.8 \%$ \\
\hline 2-pentanone & & & & $54.9 \%$ \\
\hline Methyl ester-butanoic acid & & & & $92.8 \%$ \\
\hline 3-penten-2-one & & & & $52.5 \%$ \\
\hline Pyridine & $80.1 \%$ & $83 \%$ & $81.4 \%$ & $63.5 \%$ \\
\hline 2,2, dimethodoxy butane & & & & $78.9 \%$ \\
\hline Toluene & & & & $54.8 \%$ \\
\hline Heptanol & & & & $53.2 \%$ \\
\hline 3-hexanone & & & & $35.5 \%$ \\
\hline 2-hexanone & & & & $80.7 \%$ \\
\hline Cyclopentanone & & & & $51.8 \%$ \\
\hline 1-acetylaldehyde-3-cyclopentene & & & & $45.2 \%$ \\
\hline 2-methyl cyclopentanone & & & & $60.9 \%$ \\
\hline 1,2 mono acetate ethaneidol & & & & $74 \%$ \\
\hline $\begin{array}{ll}\text { Ethylbenzene } \\
\end{array}$ & & & & $54 \%$ \\
\hline 6-phenyl tetrahydro 1,3 , oxazine-2-thione 4-methyl & $28.8 \%$ & & & \\
\hline 2-methyl cyclopenten-1-one & & & & $60.9 \%$ \\
\hline 1-(2-furanyl) ethanone & & & & $75.7 \%$ \\
\hline Butyrolactone & & & & $66.4 \%$ \\
\hline Benzaldehyde & $53.2 \%$ & $56 \%$ & $59 \%$ & \\
\hline Phenol & $51.3 \%$ & & & $67 \%$ \\
\hline Benzonitrile & & & & $65 \%$ \\
\hline Benzofuran & & & & $49.5 \%$ \\
\hline Tetrahydro furan-2-carbonyl chloride & & & & $43.9 \%$ \\
\hline 2-ethyl-1-hexanol & & & $72.8 \%$ & \\
\hline 2-hydroxy benzaldehyde & & & & $71 \%$ \\
\hline 2-methyl-phenol & & $35.6 \%$ & & $53 \%$ \\
\hline 3-methyl-phenol & & & $24.3 \%$ & \\
\hline Acetophenone & & & $16.8 \%$ & \\
\hline 2-methoxy phenol & & & & $70.4 \%$ \\
\hline Naphthalene & & & & $44.9 \%$ \\
\hline Azulene & & & & $35 \%$ \\
\hline 1-methylene-1H-indene & & $67.5 \%$ & $42.2 \%$ & \\
\hline Bi-phenyl & & & $43.1 \%$ & $66.1 \%$ \\
\hline Dibenzofuran & & & & $58.6 \%$ \\
\hline Naphtho $(2,1-b)$ furan & & $73.8 \%$ & & \\
\hline $1,2,6,6,9,9$, heptamethyl-10-methylene-spiro(2,7) dec-4-ene & & & $24.6 \%$ & \\
\hline 9-methylene 9-H-flouorene & & & & $61.8 \%$ \\
\hline
\end{tabular}


Table 2: Emitted VOCs by combustion of category $\mathrm{C}$ wood waste at temperatures of $400{ }^{\circ} \mathrm{C}, 600^{\circ} \mathrm{C}$ and $800{ }^{\circ} \mathrm{C}$

\begin{tabular}{|c|c|c|c|c|}
\hline & \multicolumn{3}{|c|}{ Temperature } \\
\hline & & $800^{\circ} \mathrm{C}$ & $600^{\circ} \mathrm{C}$ & $400{ }^{\circ} \mathrm{C}$ \\
\hline Compound & Retention time & Area $\mu V$ sec $^{-1} g^{-1}$ & Area $\mu V \sec ^{-1} g^{-1}$ & Area $\mu V \sec ^{-1} g^{-1}$ \\
\hline Unknown & 1.67 & 0 & 0 & 1701.1 \\
\hline Unknown & 1.74 & 0 & 36.09 & 1385.98 \\
\hline Unknown & 1.85 & 0.75 & 31.69 & 1430.09 \\
\hline Unknown & 1.94 & 184 & 29.3 & 1568.93 \\
\hline Heptane & 3.22 & 0.14 & 27.4 & 19.14 \\
\hline Pyridine & 5.19 & 0.28 & 6.49 & 655.35 \\
\hline Benzaldehyde & 13.25 & 0.26 & 10.28 & 0 \\
\hline 2-methyl-phenol & 16.57 & 0.25 & 48.64 & 0 \\
\hline 1-methylene-1H-indene & 21.13 & 0.42 & 56.87 & 0 \\
\hline Naphtho $(2,1-b)$ furan & 30.79 & 0.2 & 2.49 & 0 \\
\hline
\end{tabular}

Table 3: Emitted VOCs by combustion of semi-composted wood at temperatures of 500 ${ }^{\circ} \mathrm{C}$ and $850{ }^{\circ} \mathrm{C}$

\begin{tabular}{|c|c|c|c|}
\hline & \multicolumn{2}{|c|}{ Temperature } \\
\hline & & $850{ }^{\circ} \mathrm{C}$ & $500{ }^{\circ} \mathrm{C}$ \\
\hline Compound & Retention time & Area $\mu V \sec ^{-1} g^{-1}$ & Area $\mu V \sec ^{-1} g^{-1}$ \\
\hline Unknown & 1.73 & 0 & 249.77 \\
\hline Unknown & 1.79 & 100.6 & 161.16 \\
\hline Unknown & 1.98 & 133.48 & 313.9 \\
\hline Heptane & 3.24 & 172.07 & 291.92 \\
\hline Pyridine & 5.72 & 26.56 & 144.71 \\
\hline Benzaldehyde & 13.33 & 4.72 & 68.72 \\
\hline 2-ethyl-1-hexanol & 16.67 & 5.66 & 36.58 \\
\hline 1-methylene-1H-indene & 22.61 & 0.84 & 2.6 \\
\hline Bi-phenyl & 26.36 & 0.71 & 16.79 \\
\hline
\end{tabular}


Table 4: Emitted VOCs by combustion of paper waste at temperatures of $700{ }^{\circ} \mathrm{C}$

\begin{tabular}{|l|c|c|}
\hline Compound & Retention time & Area $\boldsymbol{\mu} \mathbf{V} \mathbf{~ s e c}^{\mathbf{- 1}} \mathbf{g}^{-\mathbf{1}}$ \\
\hline Unknown & 1.72 & 457.66 \\
\hline Unknown & 1.79 & 659.93 \\
\hline Unknown & 2 & 172.13 \\
\hline Heptane & 3.24 & 54.51 \\
\hline Toluene & 5.7 & 35.84 \\
\hline 2-oxo-3-cyclopentene-acetylaldehyde & 8.33 & 46.85 \\
\hline Ethylbenzene & 9.17 & 14.89 \\
\hline Benzofuran & 14.46 & 61.63 \\
\hline 2-methodoxy phenol & 18.06 & 21.2 \\
\hline Naphthalene & 21.08 & 3.97 \\
\hline
\end{tabular}

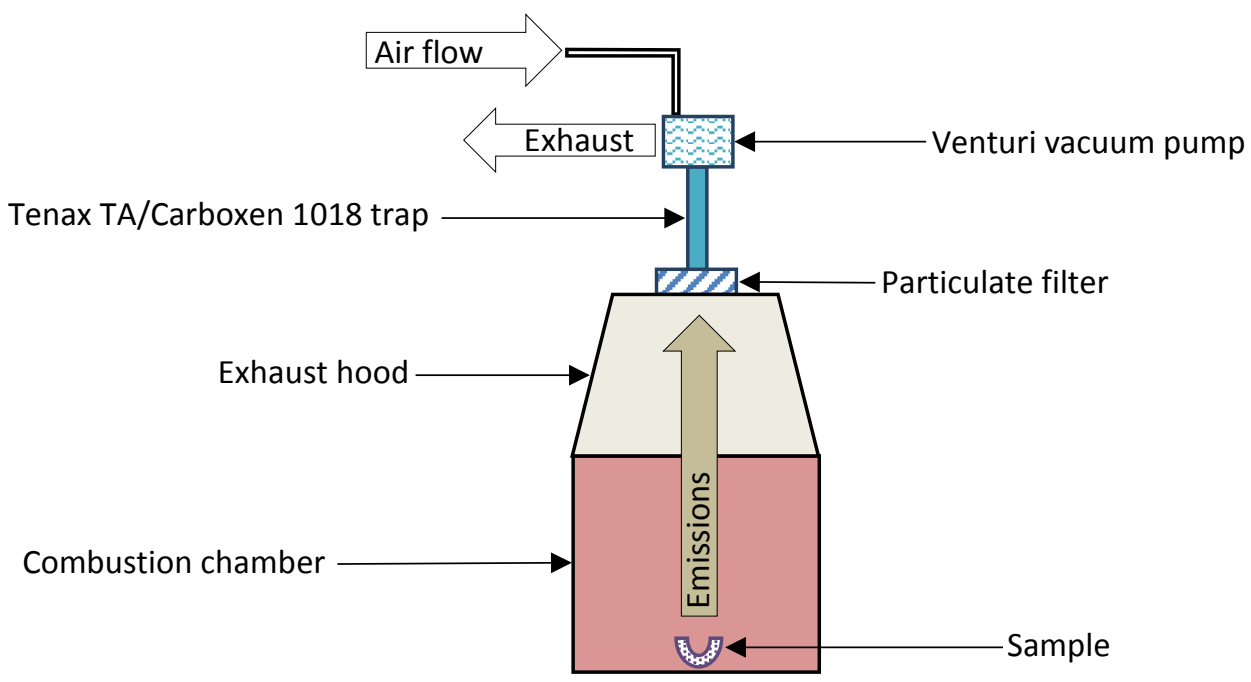

Figure 1: Schematic presentation of combustion apparatus 


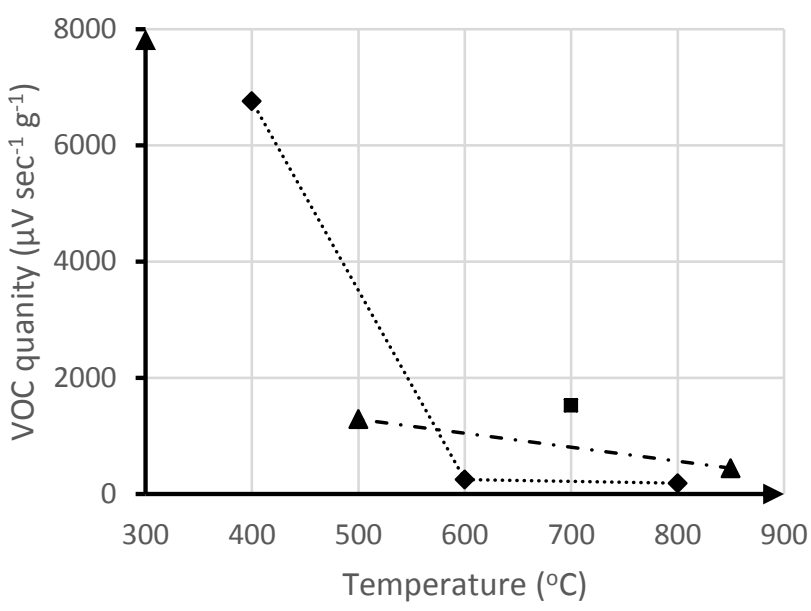

Figure 2: Total amount of VOCs emitted in different combustion temperatures 